\title{
Factors Affecting on Utilization of Reproductive Health Care Programmes in Rajasthan
}

\author{
Chamandeep Kaur $^{1 *}$, B.L. Meena ${ }^{1}$ and L.R. Choudhary ${ }^{2}$ \\ ${ }^{1}$ KVK, Sawai Madhopur, Rajasthan, India \\ ${ }^{2}$ Department of Agriculture Extension, KVK Gudamalani, Barmer, Rajasthan, India \\ *Corresponding author
}

\section{Keywords}

Reproductive health care programmes,

Panchayat samities, AIDS

\section{Article Info}

Accepted:

26 May 2020

Available Online:

10 June 2020

\section{A B S T R A C T}

The present study was conducted in Bikaner district. There were six panchayat samities out which Kolayat panchayat samities were selected by randomly chit method. Bajju, Chandasar, Diyatra and Khari villages were selected. The present study measures utilization reproductive health care $(\mathrm{RCH})$ management of rural women with a sample of 120 Pregnant and Lactating rural women. Data were collected with the help of structured interview schedules. Interview schedule developed by Laddha (2006). The Major findings were respondents belongs to below 25 years, illiterate, household, joint family, SC/ST, medium level of mass media exposure, landless, low family income. Majority of the respondents $(55 \%)$ were pregnant and had normal deliveries. Respondents were married between 19 to 22 years of age and fifteen percent had miscarriages. There were some traditional practices also done by rural women in prenatal and postnatal period. The Major findings of the respondents study revealed that the overall awareness of the rural women of Kolayat panchayat samiti related to the programme were high but utilization level of the programmes was comparatively medium. Findings further indicate that utilization level of the national AIDS control programme was very low. Age factor had significant effect on BSY, Education had significant effect on ICDS and JSY. Occupation had significant effect on RCH, type of family had significant effect on RCH, ICDS, BSY, Anganwadi meal and Kaleva. Size of Family had significant effect on RCH, BSY. Caste had significant effect on ICDS. Mass Media Exposure had significant effect on JMP and Land Holding had significant effect on ICDS, Anganwadi meal. Family Income had significant effect on BSY programme.

\section{Introduction}

Under the constitution of India, health is a significant subject. WHO defines health as
"State of Physical, Mental and Social well being which is essential for leading productive life and it is not merely the absence of illness, disease or infirmity". 
Welfare of a country depends mainly on welfare of its women as they quietly play a significant role in development of their equal status in the society. Even girl child is discriminated against male child since birth and new with technology advances even prior to birth. Existing poor health status, lack of preventive measures and obstetric care and unequal access to resources, malnutrition, lack of sex education, cultural taboos, unsafe abortion, infections, HIV etc. Result in high, maternal mortality and morbidity. The state of health in India, prior to independence, was miserably poor. With successive five year plans and sustained developmental efforts, the country has achieved significant improvement in the health status of its people. In fact, welfare of a country depends upon the welfare of its women as they contribute greatly to the development of the society. In rural areas, besides carrying out all household responsibilities, bearing children and bringing them up, they also work in the fields along with their men folk.

A number of Health programmes launched for the eradication of major communicable diseases have recorded good success. Over the years, substantial concern about women is reflected in the five year plan and as a result, various schemes and programmes for women and children have been implemented by Central Government. Programmes are Reproductive Child Health Programme (RCH), Integrated Child Development Scheme (ICDS), National Maternity Benefit Scheme (NNBS), Balika Samridhi Yojna (BSY), National Aids Control Programme (NACP), Janani Suraksha Yojana (JSY), Jan Mangal Programme (JMP), Anganwadi Meal (at Anganwadi) and Kaleva (By SHG). Madhiwall et al., (2000) studied the pattern of morbidity with and without utilizing the health facilities and expenditure on health care among women in rural and expenditure on health care among women in rural and urban of Nasik district. It was reported that morbidity among women showed link to their living environment (air, water, food) work, child bearing and contraception. Barua (2001) pointed out that only 15 per cent respondent of Assam adopted the birth control devices in the form of oral contraceptive and sterilizations. But none of the husbands reported adopting any birth control devices. Further, it was found that 80 per cent of the respondent has no knowledge about antenatal care but regarding nutrition of expectant mother, 60 per cent of them had no awareness regarding this. Education of the respondent had correlation with knowledge of antenatal care.

\section{Materials and Methods}

Survey design was used to access the utilization and awareness of the reproductive healthcare programmes regarding rural women of Kolayat Panchayat Samiti of Bikaner District. The present study was conducted in Bikaner district of Rajasthan. There are six panchayat samities in Bikaner i.e. Bikaner, Kolayat, Nokha, Sri Dungargarh, Loonkaransar and Khajuwala. Out of which Kolayat panchayat samiti was selected randomly by chit method. Four villages were selected randomly i.e. Diyatra, Chandasar, Khari and Bajju.

The respondents were selected from rural areas. There were 120 respondents pregnant and lactating (having child of the age up to 1 year) in the reproductive age group of 15-45 years were selected randomly. Thirty respondents were selected from each village. For the selection of rural respondents a comprehensive list of respondents in age group of 15-45 years were taken from Anganwadi. Thirty respondents from each village were selected randomly by using chit method. Total 120 respondents were selected as pregnant and lactating women. 


\section{Results and Discussion}

\section{Factors affecting utilization of reproductive health care programmes}

\section{Age}

Respondents age factor had significant effect on the utilization level of Balika Samridhi Yojana programme because utilization decreases with increase of the age of the respondents. Table 1 indicated that utilization level of the reproductive child health programme $(\mathrm{RCH}), \quad$ Integrated child development programme, National maternity benefit schemes, Jan Mangal Programme, Janani Suraksha Yojana, Anganwadi Meal and Kaleva are not significant effect by age factor. All the respondents had low utilization level of national AIDS control programme. So the age factor not affecting the utilization of the national AIDS control programme.

\section{Education}

Respondents education factor had significant effect on the utilization level of ICDS and JSY programme (Table 2).

\section{ICDS}

Utilization depends upon the education of the respondents. The utilization of the respondents having higher education is more as compare to respondents having low education level.

\section{JSY}

Utilization depends upon the education of the respondents. The utilization of the respondents having higher education is less as compare to the respondents having high education level.

The table further reveals that education factor had non significant effect on the utilization level of the reproductive child health programme $(\mathrm{RCH})$, National maternity benefit scheme, Balika Samridhi Yojana, Jan mangal programme, Anganwadi meal and Kaleva. All the respondents had low utilization level of national AIDS control programme. So the Education factor not affecting the utilization of the national AIDS control programme.

\section{Occupation}

Occupation had significant effect on the utilization level of the reproductive child health programme because the respondents who were not engaged in any activity, have more utilization of $\mathrm{RCH}$ programmes. Similarly, who have in service or any other activities have short time period to utilization the services of reproductive child health programmes. Table 3 depicts that occupation had non-significant effect on the utilization level of the integrated child development services, National maternity benefit schemes, Balika Samridhi Yojana, Janani Suraksha Yojana, Jan mangal programme, Anganwadi meal and Kaleva. Since utilization level of all the respondents were low so occupation not affecting utilization of the national aids control programme.

\section{Type of family}

Type of family had significant effect on the utilization level of the $\mathrm{RCH}$ programme, ICDS programme, BSY, Anganwadi meal and Kaleva. The utilization of the ICDS programme, $\mathrm{RCH}$ and BSY programme is more in nuclear family as compare to the joint family. Perhaps respondents in joint family have short period of time to visit the centre. The utilization of Anganwadi meal and kaleva programme depends upon the size of family. The respondents who has joint family, utilizes this service more as compare to the respondents having nuclear family. Table 4 reveals that type of family had not significant 
effect on the utilization level of the national maternity benefit schemes, Janani Suraksha Yojana, Jan Mangal programme. Since, the utilization level of the respondents were low so, type of family not affecting the utilization of the national AIDS control programme.

\section{Size of family}

Size of family had significant effect on the utilization level of the reproductive child health programme and Balika Samridhi Yojana because the utilization of these programme is more by the respondents who have small family as compared to large family size. The Table 5 show that size of family had non-significant effect on the utilization level of ICDS, BSY, JSY, JMP, Anganwadi meal and Kaleva. Utilization level of all the respondents were low that's why size of family not affecting utilization of National AIDS control programme.

Table.1 Age affecting with various reproductive health care programmes

\begin{tabular}{|r|l|c|}
\hline S. No. & Name of the programme & Chi-square \\
\hline $\mathbf{1 .}$ & RCH & $2.803 \mathrm{NS}$ \\
\hline $\mathbf{2 .}$ & ICDS & $0.082 \mathrm{NS}$ \\
\hline $\mathbf{3 .}$ & NMBS & $2.079 \mathrm{NS}$ \\
\hline $\mathbf{4 .}$ & BSY & $3.926^{*}$ \\
\hline $\mathbf{5 .}$ & NACP & \#Div/0! \\
\hline $\mathbf{6 .}$ & JSY & $0.003 \mathrm{NS}$ \\
\hline $\mathbf{7 .}$ & JMP & $0.396 \mathrm{NS}$ \\
\hline $\mathbf{8 .}$ & Anganwadi Meal & $0.008 \mathrm{NS}$ \\
\hline $\mathbf{9 .}$ & Kaleva & $0.719 \mathrm{NS}$ \\
\hline \multicolumn{2}{|c|}{ NS $=$ Non Significant } & $\mathbf{0 . 0 0 6}$ NS \\
\hline \multicolumn{3}{|c|}{} \\
\hline
\end{tabular}

Table.2 Education affecting with various reproductive health care programmes

\begin{tabular}{|r|l|c|}
\hline S. No. & Name of the programme & Chi-square \\
\hline $\mathbf{1 .}$ & RCH & $1.565 \mathrm{NS}$ \\
\hline $\mathbf{2 .}$ & ICDS & $10.432 *$ \\
\hline $\mathbf{3 .}$ & NMBS & $1.577 \mathrm{NS}$ \\
\hline $\mathbf{4 .}$ & BSY & $1.368 \mathrm{NS}$ \\
\hline $\mathbf{5 .}$ & NACP & \#Div/0! \\
\hline $\mathbf{6 .}$ & JSY & $11.222^{*} *$ \\
\hline $\mathbf{7 .}$ & JMP & $3.332 \mathrm{NS}$ \\
\hline $\mathbf{8 .}$ & Anganwadi Meal & $0.329 \mathrm{NS}$ \\
\hline $\mathbf{9 .}$ & Kaleva & $3.454 \mathrm{NS}$ \\
\hline \multicolumn{2}{|c|}{ Overall } & $\mathbf{2 . 9 3 9} \mathrm{NS}$ \\
\hline \multicolumn{2}{|c|}{$=$ Non Significant } \\
\multirow{2}{*}{$=$} & Significant at 0.05 level of significance \\
$* *$ & $=$ Significant at 0.01 level of significance \\
\hline
\end{tabular}


Table.3 Occupation affecting with various reproductive health care programmes

\begin{tabular}{|c|c|c|}
\hline S. No. & Name of the programme & Chi-square \\
\hline 1. & $\mathrm{RCH}$ & $7.667 * *$ \\
\hline 2. & ICDS & $2.024 \mathrm{NS}$ \\
\hline 3. & NMBS & $0.967 \mathrm{NS}$ \\
\hline 4. & BSY & $4.085 \mathrm{NS}$ \\
\hline 5. & NACP & \#Div/0! \\
\hline 6. & JSY & $2.240 \mathrm{NS}$ \\
\hline 7. & JMP & $0.058 \mathrm{NS}$ \\
\hline 8. & Anganwadi Meal & $1.452 \mathrm{NS}$ \\
\hline 9. & Kaleva & $0.539 \mathrm{NS}$ \\
\hline & Overall & $2.023 \mathrm{NS}$ \\
\hline
\end{tabular}

NS $=$ Non Significant

$* *=$ Significant at 0.01 level of significance

Table.4 Type of family affecting with various reproductive health care programmes

\begin{tabular}{|r|l|c|}
\hline S. No. & Name of the programme & Chi-square \\
\hline $\mathbf{1 .}$ & RCH & $4.895^{*}$ \\
\hline $\mathbf{2 .}$ & ICDS & $13.866^{* *}$ \\
\hline $\mathbf{3 .}$ & NMBS & $0.189 \mathrm{NS}$ \\
\hline $\mathbf{4 .}$ & BSY & $6.280^{*}$ \\
\hline $\mathbf{5 .}$ & NACP & \#Div/0! \\
\hline $\mathbf{6 .}$ & JSY & $0.791 \mathrm{NS}$ \\
\hline $\mathbf{7 .}$ & JMP & $1.784 \mathrm{NS}$ \\
\hline $\mathbf{8 .}$ & Anganwadi Meal & $4.220^{*}$ \\
\hline $\mathbf{9 .}$ & Kaleva & $4.021^{*}$ \\
\hline & & $\mathbf{0 . 0 1 8} \mathbf{N S}$ \\
\hline
\end{tabular}

* $=$ Significant at 0.05 level of significance

$* *=$ Significant at 0.01 level of significance

Table.5 Size of family affecting with various reproductive health care programmes

\begin{tabular}{|c|c|c|}
\hline S. No. & Name of the programme & Chi-square \\
\hline 1. & $\mathrm{RCH}$ & $9.358 * *$ \\
\hline 2. & ICDS & $1.763 \mathrm{NS}$ \\
\hline 3. & NMBS & $1.210 \mathrm{NS}$ \\
\hline 4. & BSY & $7.884 * *$ \\
\hline 5. & $\mathrm{NACP}$ & \#Div/0! \\
\hline 6. & JSY & $0.772 \mathrm{NS}$ \\
\hline 7. & JMP & $0.770 \mathrm{NS}$ \\
\hline 8. & Anganwadi Meal & $0.110 \mathrm{NS}$ \\
\hline \multirow[t]{2}{*}{9.} & Kaleva & $5.554 \mathrm{NS}$ \\
\hline & Overall & 2.683 NS \\
\hline
\end{tabular}

NS $=$ Non Significant

** = Significant at 0.01 level of significance 
Table.6 MME affecting with various reproductive health care programmes

\begin{tabular}{|c|l|c|}
\hline S. No. & Name of the programme & Chi-square \\
\hline $\mathbf{1 .}$ & RCH & $2.626 \mathrm{NS}$ \\
\hline $\mathbf{2 .}$ & ICDS & $0.371 \mathrm{NS}$ \\
\hline $\mathbf{3 .}$ & NMBS & $0.207 \mathrm{NS}$ \\
\hline $\mathbf{4 .}$ & BSY & $1.094 \mathrm{NS}$ \\
\hline $\mathbf{5 .}$ & NACP & \#Div/0! \\
\hline $\mathbf{6 .}$ & JSY & $1.432 \mathrm{NS}$ \\
\hline $\mathbf{7 .}$ & JMP & $0.211^{* *}$ \\
\hline $\mathbf{8 .}$ & Anganwadi Meal & $0.426 \mathrm{NS}$ \\
\hline $\mathbf{9 .}$ & Kaleva & $1.388 \mathrm{NS}$ \\
\hline & & $\mathbf{1 . 1 6 0} \mathbf{N S}$ \\
\hline
\end{tabular}

$* *=$ Significant at 0.01 level of significance

\section{Mass Media Exposure (MME)}

Mass media exposure had significant effect on the utilization level of the Jan Mangal programme because with increase of the mass media exposure the utilization also increased.

The Table 6 reveals the mass media exposure had non significant effect on the utilization level of the RCH, ICDS, NMBS, BSY, JSY, Anganwadi meal and kaleva. Utilization level of all the respondents was low so, mass media exposure not affecting utilization of national AIDS control programmes.

From the above finding it can be concluded that majority of the respondents were in age group of below 25 years, illiterate ,household, kuccha house, joint family, medium size, ST/SC, No social participation, low mass media exposure, agricultural labour, landless, respondents income nil, low family income. Majority of the respondents were pregnant, marriage age was 1218 years, husband's age of marriage below 21 years, age of gaunna was 18 and above, normal delivery. An Assessment of awareness and utilization of the reproductive health care programme show that awareness of the programme were high and utilization level was medium caste factor had significant effect on the utilization level of all the programmes with degree of freedom 2. All the respondents had low utilization level of national AIDS control programme. So, there was no significant effect on any factor.

\section{References}

Laddha S. (2006). Reproductive health care management pattern of rural women. Sunita Laddha 2002 HS 119 D. I.C. College of Home Science, Department of family resources Management CCS Haryana Agricultural University, Hissar125004.

Madhiwal, S., Bhasin, S.K., Aggarwal, O.P. and Khan, A.T. (2000). Knowledge and practices of mothers regarding health. www.int/reproductive health.

Roth, D. (1998) Asking women why: A study in Tanzania. World Health. 51(1): 6-7.

\section{How to cite this article:}

Chamandeep Kaur, B.L. Meena and Choudhary, L.R. 2020. Factors Affecting on Utilization of Reproductive Health Care Programmes in Rajasthan. Int.J.Curr.Microbiol.App.Sci. 9(06): 3624-3629. doi: https://doi.org/10.20546/ijcmas.2020.906.426 